\title{
Flood Modeling and Simulation using iRIC: A Case Study of Kabul City
}

\author{
Jamal Abdul Naser Shokory ${ }^{1, a}$, Jun-ichiro Giorgos Tsutsumi ${ }^{1}$ and Kazuhito Sakai ${ }^{2}$ \\ ${ }^{1}$ Department of Civil Engineering and Architecture, Faculty of Engineering, University of the Ryukyus, Senbaru 1, Nishihara, Okinawa \\ 903-0213 JAPAN \\ ${ }^{2}$ Department of Regional Agricultural Engineering, Faculty of Agriculture, University of the Ryukyus, Senbaru 1, Nishihara, Okinawa \\ 903-0213 JAPAN
}

\begin{abstract}
In Afghanistan, floods are common and measures must be taken to protect people and property from damage. There is, however, a lack of detailed observations and research on this subject in this area. Therefore, flood simulation models are needed to identify flood-prone areas. In this study, International River Interface Cooperative (iRIC) program that is river flow and riverbed variation analysis software with several solvers has been used. Nays2DFlood solver that simulates 2dimenstional plane flow has applied to a past flood in Kabul city. River discharge from two inflow points and averaged precipitation from three rain gauges at the time of flooding given as input to the model including DEM (Digital Elevation Model) data. The iRIC was confirmed as a 90-m grid digital elevation model to determine the position of streamlines correctly. However, the highest flood depth was overestimated because the $90-\mathrm{m}$ grids were too coarse to detect the slight slope of the riverbed in some areas. Then the elevation of the riverbed modified using data acquired from Google Earth, and the simulation results improved. Moreover, it was found that river water rather than rainfall was the main cause of the flooding.
\end{abstract}

\section{Introduction}

A flood is "the overflowing of the normal confines of a stream or other body of water, or the accumulation of water in areas that are not normally submerged. Floods are affected by various characteristics of precipitation, such as intensity, duration, amount, timing, and phase (rain or snow)" [1]. Flash floods are powerful enough to sweep entire houses and bridges away, cause severe and costly damage, and are the primary cause of loss of life in Afghanistan [2]. Afghanistan has always been under the periodic threat of flooding due to intense rainfall, melting snow, or a combination of both. Every year, there are many fatalities and thousands of homes are destroyed as a result of floods [3]. The international disaster database reported that $54.3 \%$ of all natural disasters in Afghanistan are flood related, and the average annual economic loss was US\$92.17 million from 1990 to 2014 [4].

The capital of Afghanistan, Kabul, is also the country's largest city [4]. Its population was about $3,289,000$ in 2012 [5], and it is currently the fifth fastest growing city in the world [6]. Most of the rainfall occurs in April, with the rain events lasting either 1-2 or 3-7 days [7]. In Table 1 a summary of the damage caused by floods in Kabul from 2005 to 2007 is presented. Although the damage varies annually, the numbers of damaged dwellings are large [8]. Many of the most vulnerable houses are constructed in unplanned areas. They are at risk of damage by both earthquakes and floods [9], primarily because the main construction materials used are clay and clay bricks, both of which are susceptible to damage during floods and heavy rainfall events. Flood hazard areas have been identified along the administrative boundary between districts 5 and 13 (Figure 1) [8].

In Afghanistan, even basic information is lacking to describe the type of floods, the cause of floods, and the temporal window when floods can be expected. A nationor region-wide map is needed indicating areas that require further investigation and where mitigation studies might be useful [10].

Accordingly, Emlyn Hagen from North Atlantic Treaty Organization introduced the Flood Hazard Mapping Project for Afghanistan in 2008. Utilized a kind of cellular automata in which various amounts of water were simulated by computer to fill up one cell and then flow into the next automaton cell. The data were calibrated using available information from past flood events and remote sensing observational data from the Dartmouth Flood Observatory [11]. However, according to the IPCC Fifth Assessment Report, there is a high likelihood of earlier occurrences of spring's peak river flows in snowmelt- and glacier-fed rivers. Moreover, it is likely that the frequency of heavy precipitation or the proportion of total rainfall from heavy rainfalls will increase in the $21 \mathrm{st}$ century in many areas of the globe [1]. If these predictions come true, they will affect future flood-prone areas. Therefore, using only past flood data may be not sufficient to establish flood protection plans in the future. Moreover, most of the river flows in

\footnotetext{
${ }^{\mathrm{a}}$ Corresponding author: jamalnaser.shokory@gmail.com
} 
Afghanistan depend on the amount of annual rain and snowfall [12].

\begin{tabular}{|c|c|c|c|c|c|}
\hline \multirow{2}{*}{  } & \multicolumn{3}{|c|}{ No. People affected } & \multicolumn{2}{|c|}{ No. Of dwellings } \\
\hline & Missing & Killed & Injured & $\begin{array}{l}\text { Partially } \\
\text { damaged }\end{array}$ & Destroyed \\
\hline 2005 & 0 & 0 & 0 & 67 & 106 \\
\hline 2006 & 0 & 12 & 9 & 150 & 0 \\
\hline 2007 & 0 & 14 & 10 & 645 & 281 \\
\hline
\end{tabular}

Table 1. Major Floods in Kabul.

Source: DMIS (Disaster Management Information System), National Anti-Disaster Department

A method to estimate future floods in Afghanistan has not yet been developed. Also, the public monitoring system of flooding in Afghanistan has not been sufficiently developed, and the amount of available data that can be easily obtained is limited. Therefore, a simulation system that can work with a limited amount of data is required. Simulation software is required to develop a simulation system because it takes a long time to write source code for a simulation model, creating simulation systems is challenging. Recently, the International River Interface Cooperative (iRIC) software application was developed specially for river flow analysis in developing countries. iRIC has several solvers, and the Nays2DFlood solver is used for flood analysis. In this study, the iRIC Nays2DFlood solver and flood data that was easily attainable from the Internet for Kabul city was used to evaluate the applicability of iRIC to flood analysis and examine the influence of rainfall and river water on flooding in the area.

\section{Material and Methods}

\subsection{Study Area}

The study area included districts 3, 5, 6, 7, and 13 of Kabul city (Figure 1). The total area was $166.6 \mathrm{~km}^{2}$; in 2012 , there were $1,148,800$ people living in 192,200 households in this area [5]. The downtown area is almost all floodplain, surrounded by mountains and steep hillsides. Kabul River flows through the city and originates in the high mountains to the east of the city's plain area. The river crosses the middle of the city and combines with two tributaries flowing from the west [13]. Most of the residences are located along the rivers.

There are two main problems during flooding. (1) The rainwater drainage system that collects rainwater in roadside ditches is not properly connected to main drains. Most of the rainwater drains were developed at the time of road construction, and rehabilitation and integrated and efficient drainage systems were not established at that time. Accordingly, many streets are often submerged by storm water during heavy rainfall [8]. (2) The downstream area where the river crosses the city is almost flat. Sediments transferred from the steep upstream hillsides and mountains have raised the riverbed, thereby causing the river to overflow during heavy rainfall events.

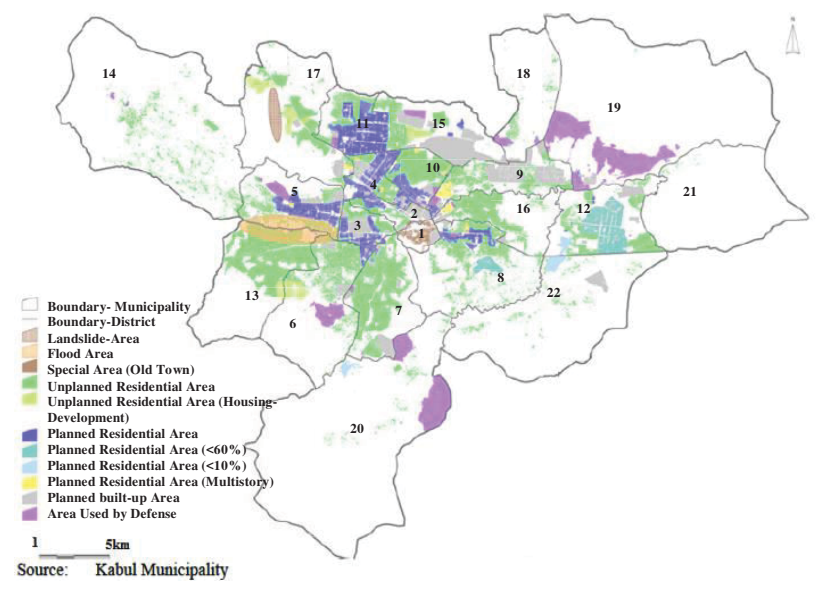

Figure 1. Map of Kabul city (districts are numbered)

\section{2 iRIC Nays2DFlood}

Nays2Dflood is a 2-dimensnional, Flood flow simulation modeling program considering boundaryfitted coordinates or a rectangular coordinate system to general curvilinear coordinate system. Figure 2 shows the iRIC-Nays2DFlood window. There are different subwindows; Pre-processing window where the data has prepared, and calculation condition was set, Solver window runs the simulation, and Post-processing windows visualized the result. The program does not require river channel data; it can grasp from input DEM (Digital Elevation Model) data. It is easy to set inflow points of upstream and sides over terrain by considering background image. The model enable to set various parameter for boundary condition, the bottom friction of the river is set using Manning's roughness coefficient for this study it was 0.025 (Figure 4a). This model has examined to simulate floods of small and mid-scale rivers and applicable for flood process simulation of rivers in development countries [14].



Figure 2. iRIC Nays2DFlood-solver window, Preprocessing window, Solver window, and Post-processing windows.

\subsubsection{Model equations and work steps}

The model is running based on following equations; Equation of continuity

$$
\frac{\partial \mathrm{h}}{\partial \mathrm{t}}+\frac{\partial(\mathrm{hu})}{\partial \mathrm{x}}+\frac{\partial(\mathrm{hv})}{\partial \mathrm{t}}=\mathrm{q}+\mathrm{r}
$$




$$
\begin{aligned}
& \frac{\partial(u h)}{\partial t}+\frac{\partial\left(h u^{2}\right)}{\partial x}+\frac{\partial(h u v)}{\partial y}=-h g \frac{\partial H}{\partial x}-\frac{\tau_{x}}{\rho}+D^{x} \\
& \frac{\partial(v h)}{\partial t}+\frac{\partial(h u v)}{\partial x}+\frac{\partial\left(h v^{2}\right)}{\partial y}=-h g \frac{\partial H}{\partial y}-\frac{\tau_{y}}{\rho}+D^{y} \\
& \frac{\tau_{x}}{\rho}=C_{f} u \sqrt{u^{2}+v^{2}} \quad \frac{\tau_{y}}{\rho}=C_{f} v \sqrt{u^{2}+v^{2}} \\
& D^{x}=\frac{\partial}{\partial x}\left[v_{t} \frac{\partial(u h)}{\partial x}\right]+\frac{\partial}{\partial y}\left[v_{t} \frac{\partial(u h)}{\partial y}\right] \\
& D^{y}=\frac{\partial}{\partial x}\left[v_{t} \frac{\partial(v h)}{\partial x}\right]+\frac{\partial}{\partial y}\left[v_{t} \frac{\partial(v h)}{\partial y}\right]
\end{aligned}
$$

Where, $h$ is water depth, $t$ is time, $u$ is flow velocity in the $x$ direction, $v$ is flow velocity in the $y$ direction, $g$ is gravitational acceleration, $H$ is water surface elevation,

is riverbed shear stress in the $x$-direction, is riverbed shear stress in the $y$-direction, $\quad f$ is the riverbed friction coefficient, is the eddy viscosity coefficient, and $\rho$ is the density of water, $\mathrm{q}$ is inflow through a box culvert, a sluice pipe or a pump per unit area, and $r$ is rainfall. Details on the calculations are provided on the iRIC web page [14].

The overall workflow of flood simulation is shown in Figure 3.

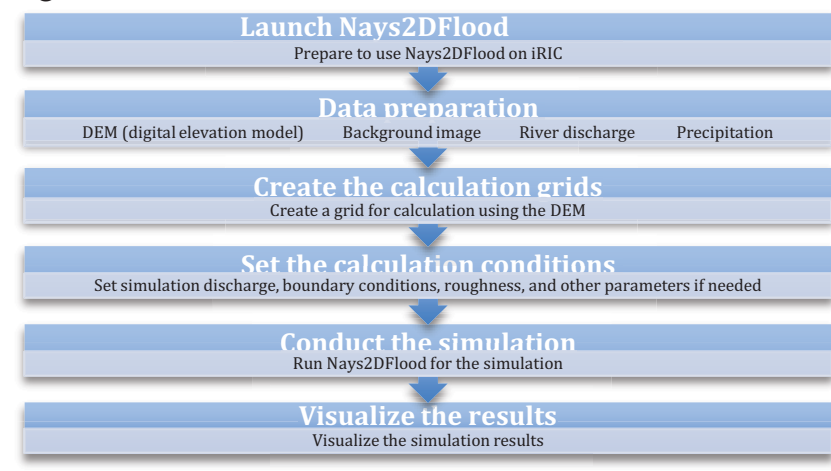

Figure 3. Procedure for operating the Nays2DFlood solver with iRIC.

\subsubsection{Data preparation and simulation}

It is important to decide accurate digital elevation model (DEM) for simulation. The DEM used in this study was a 90-m grid downloaded from SRTM DEM [15]. Because of random and small deviations in the elevation surface of DEM caused sinks [16], we tried to modify the sinks by using ArcGIS software. However, "narrow gorges can merge and form obstacles with extreme elevation differences $(>50 \mathrm{~m})$ in mountainous areas" [10]. In the study area, the filling sink method could result in wide flat surfaces, including the branching of valleys, and then DEM was used as original.

For the background image, we used an image obtained from Google Earth. By overlaying the DEM and the background image, two inflow points were determined: Tangi Saydan located on the south side of the city and Qala e Malik located on the west side of the city (Figure 4).

Because the flood peak started on 19 April 2012 (Figure 5), we analyzed data from 12:00 19 April to 18:00 21 April 2012 in the simulation. The hourly precipitation data from three rain gauge stations and daily discharge data (hourly data were not available) for the two inflow points were obtained from the Ministry of Energy and Water of Afghanistan [17] (Figure 6). Maximum discharge at the time of the flooding at Tangi Saydan station was about $80 \mathrm{~m} 3 / \mathrm{s}$. This value is close to the highest value ever recorded $(86 \mathrm{~m} 3 / \mathrm{s})$ at this station on 27 April 1967. Log-normal Distribution probability method applied to realize the return period of yearly maximum discharge peak, which showed this extreme condition will return about every 12 years (Figure 7) [18].

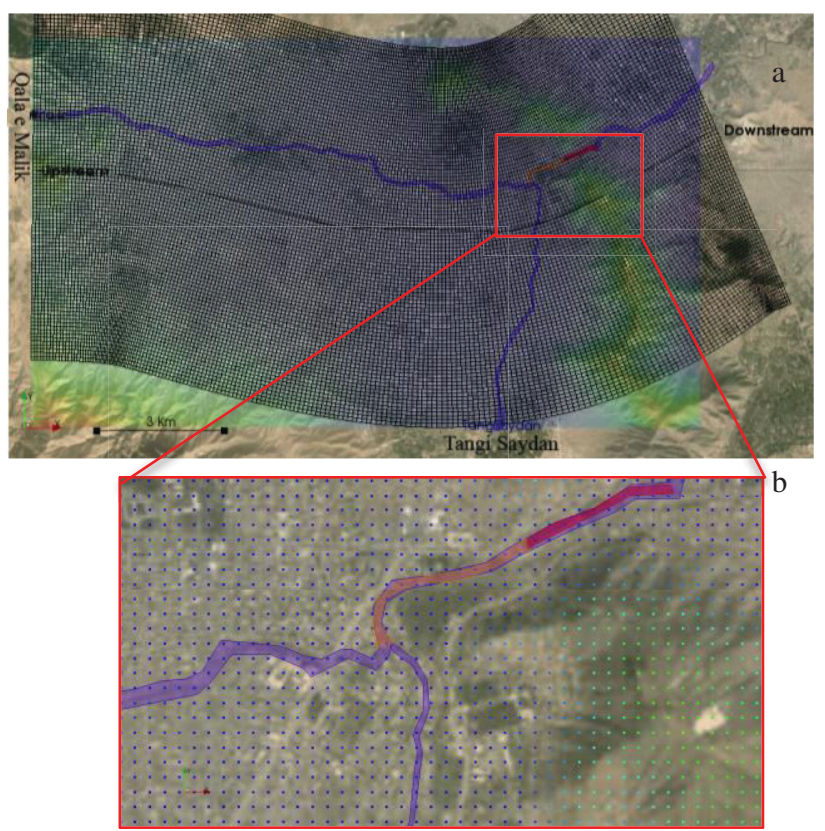

Figure 4. (a) Calculation grid map, colored image shows DEM of the study area with the background image from Google Earth. Blue polygon is roughness setting. Qala e Malik and Tangi Saydan are the inflow points. (b) Orange and purple polygons are modified elevations of the river, dots are the DEM elevation points.

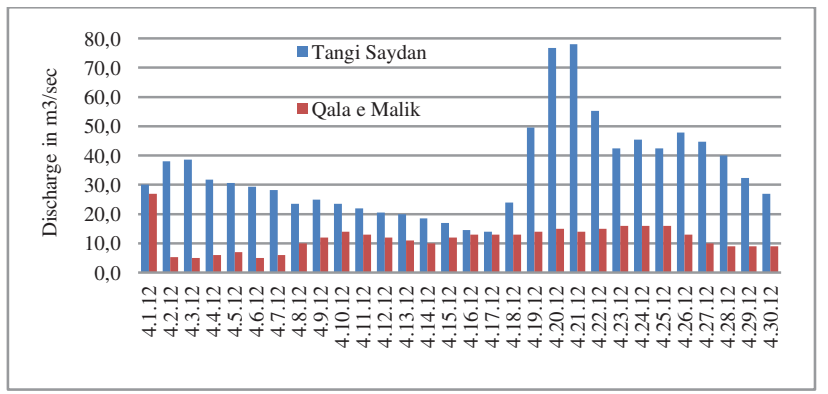

Figure 5. Daily discharge from two points in Kabul where inputted as hourly at the Model.

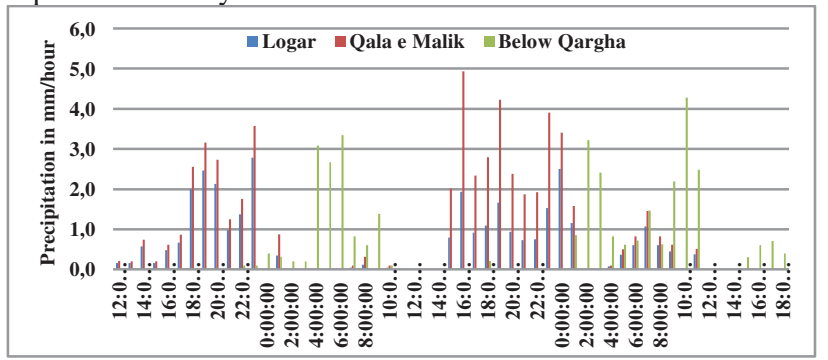

Figure 6. Hourly precipitation during the period of flooding (12:00 19 April to 18:00 21 April 2012) as recorded at three rain gauge stations. 


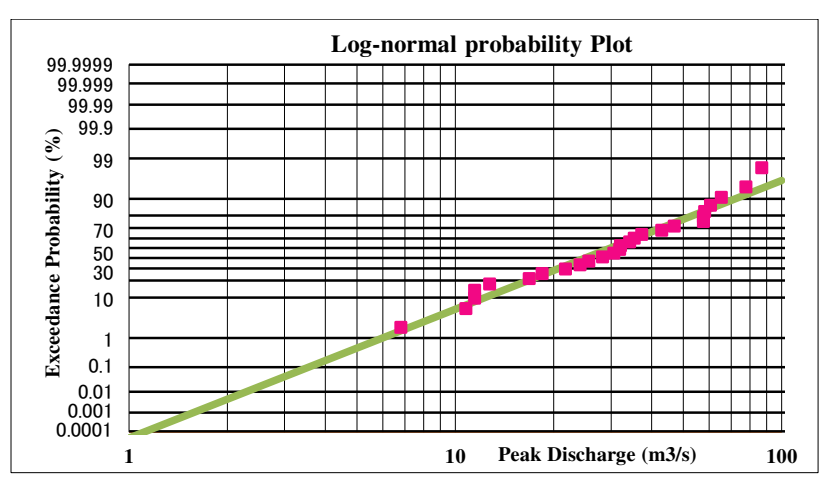

Figure 7. Log-normal probability plot of 26 years annual peak discharge data (1962-1980,2008-2014).

\section{Results and Discussion}

\subsection{Simulation with the original DEM}

The original DEM applied to the iRIC-Nays2DFlood solver, the result obtained a flood depth map (Figure 8), velocity magnitude map (Figure 9), and velocity vectors map (Figure 10).

By comparing Figure 9 to the background map, it is confirmed that the iRIC could correctly identify the streamline using the 90-m DEM. However, the maximum flood depth of $7.0 \mathrm{~m}$ was not realistic (Figure 8), and the velocity magnitude downstream of the flood area with the maximum depth was too low (Figures 9 and 10). We, therefore, examined the elevation data for that area. It was discovered that there were no differences in the elevation in grids of the streamline because the program could not detect the gentle slope from the 90-m DEM. Therefore; some of the elevation data modified manually according to information obtained from Google Earth.

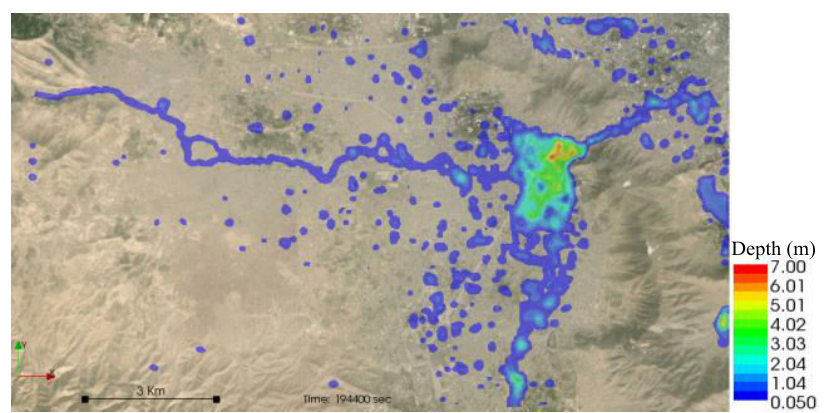

Figure 8. Flood depth map of the study area from the $90-\mathrm{m}$ DEM.

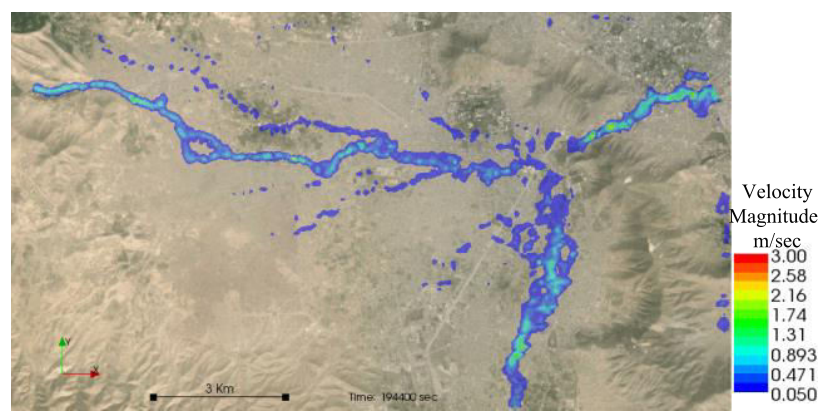

Figure 9. Velocity magnitude map of the study area from the 90-m DEM.

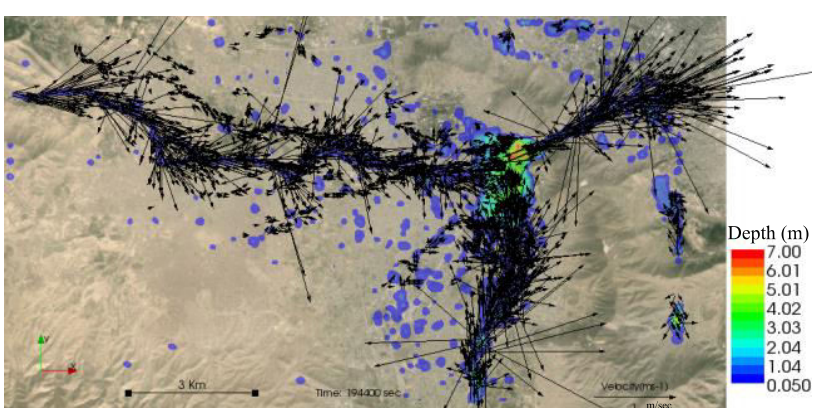

Figure 10. Velocity vector map of the study area from the $90-\mathrm{m}$ DEM.

\subsection{Simulation with the modified DEM}

A modification was done to the original DEM and applied to the Nays2DFlood solver to obtain a new flood depth map (Figure 12), velocity magnitude map (Figure 13), and velocity vectors map (Figure 14). The Flood could not pass over original DEM in the model (Figure 11a); this brought the question that there might be an obstacle. Then the same position zoomed in at the Google Earth to examine the obstacle; it showed that the river has continuation without any obstacles. The elevation points of the original DEM have not covered river where river wide was about 40 meter, this data modified with information obtained from Google Earth by adding elevation polygons in iRIC (Figure 4b). From Figure 12, it could confirm that the maximum simulated flood depth was about $2 \mathrm{~m}$ out of the streamline and $4.5 \mathrm{~m}$ in the centerline of the river. This value considered being more realistic than simulation results obtained with the original DEM. Moreover, from Figures 13 and 14, we could confirm that there was water flow downstream of the flooded area.

As it was difficult to get the observational data for the flood to validate the result, therefor the information from a news report of the flood [19] used to validate the model (Figure 15). Although the iRIC could not validate quantitatively because of a lack of data, visually confirm that the simulated flooded areas corresponded to the actual flooded areas shown in the news report. The results concluded that the iRIC model can be used to simulate flooding using data that could obtain with comparative ease from the Internet.



Figure 11. (a) Original DEM at $72720 \mathrm{sec}$, The DEM could not pass the Flood. (b) Modified DEM at $72720 \mathrm{sec}$, the Flood covered certain area. 


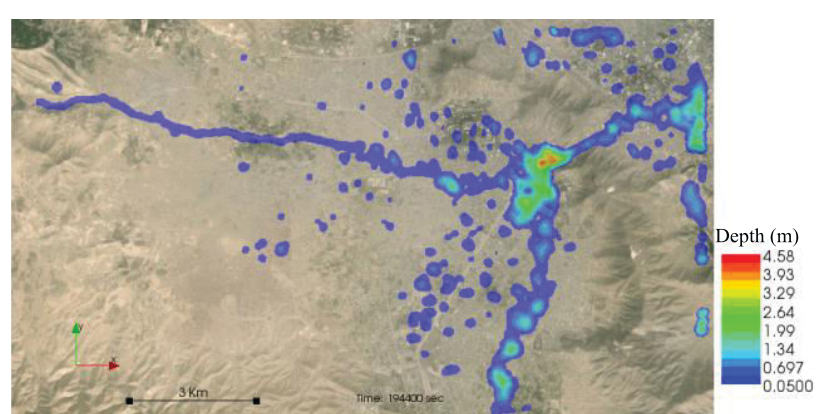

Figure 12. Flood depth map of the study area from the $90-\mathrm{m}$ modified DEM.



Figure 13. Velocity magnitude map of the study area from the 90-m modified DEM

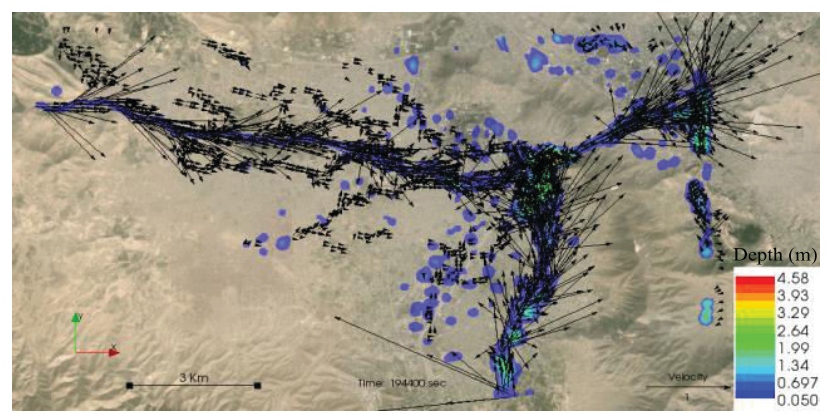

Figure 14. Velocity vector map of the study area from the $90-\mathrm{m}$ modified DEM

\subsection{Examination of the influence of rainfall and river water}

The solver helped to examine the influence of rainfall and river water by excluding and including the rainfall data. The simulated result (Figure 16) showed that flood depth was lower than that of the modified DEM case that included rainfall data (Figure 12), but the difference was not large. This comparison indicates that the main cause of the flood was the river water rather than the rainfall. The effects of rainfall can be seen in some areas as a pound (Figure 12), primarily where the drainage system is not well connected (Figure 15a). Moreover, the slope in the downstream areas was quite shallow, which also contributes to poor drainage. Therefore, the results suggest that dredging the riverbed in these areas would increase drainage capacity and be an effective measure for flood protection.
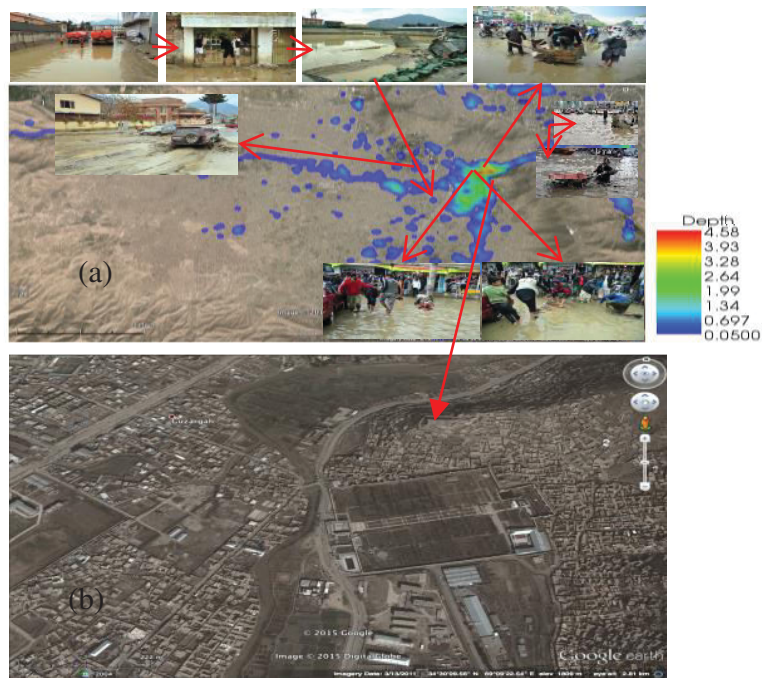

Figure 15. (a) The modeled flooded area compared with photos in a news report of the flood [19]; (b) a Google Earth magnified image of the flood area.

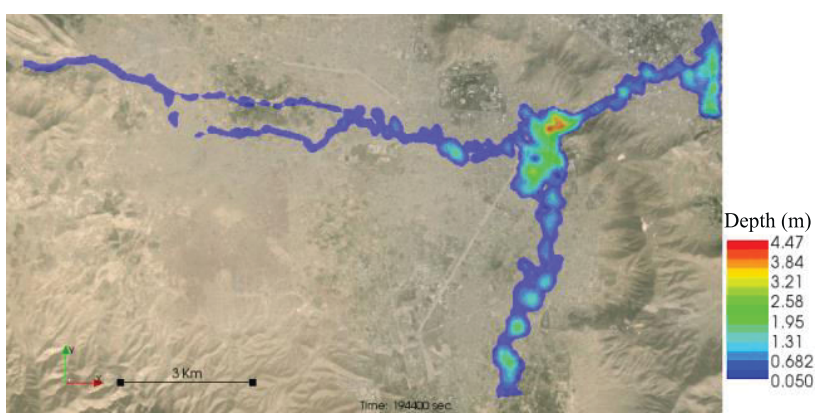

Figure 16. Flood depth map of the study area from the $90-\mathrm{m}$ modified DEM without rainfall data.

\section{Conclusions}

The Nays2DFlood solver with iRIC applied to model a past flood event in Kabul city using data that was easily obtainable on the Internet. Concluded parts are as follows:

1) The iRIC could model the streamline correctly using the 90-m grid DEM.

2) When the river flowed in relatively flat areas, it was difficult to distinguish small changes in elevation using the 90-m grid DEM. We, therefore, had to modify the elevation in these areas to determine better the streamline.

3) We were able to simulate a flood in Kabul city using the modified DEM successfully.

4) The influence of river water was larger than that of the rainfall in flooded areas.

5) If forecasted data (river discharge and precipitation) used as input the output would be forecasted flood using this model.

6) The results will make possible to avoid constructing buildings in hazard zones or implement mitigation measures to protect infrastructure, thus saving millions of dollars in investments. 


\section{References}

1. Seneviratne S. I., Nicholls N., Easterling D., Goodess C. M., Kanae S., Kossin J., ... Zhang X. (2012). Changes in climate extremes and their impacts on the natural physical environment. Managing the risks of extreme events and disasters to advance climate change adaptation. IPCC, 109-230. http://ipccwg2.gov/SREX/images/uploads/SREXChap3_FINAL.pdf

2. Jones J. A., Vardanian T., Hakopian C. (2009). Threats to global water security, Eds; Springer Science \& Business Media. pp. 179-185.

3. NATO-News. Satellite map helps predict floods in Afghanistan.

http://www.nato.int/cps/en/natohq/news_56368.htm? selectedLocale=en(16.May.2015).

4. Prevention Web.net. Afghanistan. http://www.preventionweb.net/countries/afg/data/ (16.May.2015).

5. CSO (Central Statistics Organization). Afghanistan Statistical Yearbook 2012/13. http://cso.gov.af/Content/files/Population of Kabul City by District and Sex.pdf (16.May.2015).

6. CITY MAYORS STATISTICS. The world's fastest growing cities and urban areas from 2006 to 2020. http://www.citymayors.com/statistics/urban_growth1 .html (16.May.2015).

7. Dartmouth Flood Observatory. Duration of Floods Since (1985).

http://floodobservatory.colorado.edu/archiveatlas/dur ationmonthmap.htm (16.May.2015).

8. Takashi Koyama of RECS International Inc., Yachiyo Engineering Co., Ltd., and CTI Engineering International Co., Ltd. Draft Kabul City Master Plan. JICA $20116.1-6.56$

http://pdf.usaid.gov/pdf_docs/pa00jmmj.pdf

9. IRIN humanitarian news and analysis. AFGHANISTAN: Unsafe housing puts Kabul residents at risk.

http://www.irinnews.org/report/85585/ (16.May.2015).

10. Hagen E., Shroder J. F., Lu X. X., and Teufert J. F. (2010). Reverse engineered flood hazard mapping in Afghanistan: A parsimonious flood map model for developing countries. Quaternary International, 226(1-2): 82-91.

http://www.sciencedirect.com/science/article /pii/S1040618209004273.

11. Shroder, Jones E. (2014). Natural Resources in Afghanistan, 1st ed.; ELSEVIER. Waltham, USA, pp. 253-258.

12. Favre R., and Kamal G. M. (2004). Watershed atlas of Afghanistan. Kabul: Ministry of Irriga. Aizon, I-II, 20-37 http://aizon.org/Watershed Atlas of Afghansitan/Volume I/Watershed Atlas_Part I \& $\underline{\text { II.pdf }}$

13. Lashkaripour G. R., and Hussaini S. A. (2008). Water resource management in Kabul river basin, eastern Afghanistan. The Environmentalist, 28(3), 253-260.

http://www.researchgate.net/publication/225906403
Water_resource_management_in_Kabul_river_basin _eastern_Afghanistan

14. Takuya I., and Toshiki I. (2012) Nays2D Flood Solver Manual. iRIC Project, 1-25. http://iric.org/en/download/get/KNwWfa

15. SRTM DEM Shuttle Radar Topography Mission http://www.viewfinderpanoramas.org/Coverage map viewfinderpanorama s_org3.htm (16.May.2015).

16. Lehner B., Verdin K., and Jarvis A. (2006). HydroSHEDS Technical Documentation. World Wildlife Fund US, Washington, DC, 1-27. http://hydrosheds.cr.usgs.gov/webappcontent/Hydro SHEDS_TechDoc_v10.pdf

17. MEW (Ministry of Energy and Water) Afghanistan, Water Resources Department. http://mew.gov.af/en (Add: Darullaman Road, 6th district, Kabul Afghanistan. Data was asked directly from Ministry office and it is not available in website)

18. Pajhwok News: Flash Flood in Kabul Apr.2012 http://www.pajhwok.com/en/photo/176592 (16.Apr.2014).

19. Wikipedia: Log-normal distribution https://en.wikipedia.org/wiki/Lognormal_distribution (20.Oct.2015).

20. Takuya, I.; Toshiki, I. Nays2D Flood Examples. iRIC Project 2013, 1-87. http://iric.org/en/download/get/zdd4wJ

21. fernan J. E., and Tawn J. A. (2004). A conditional approach for multivariate extreme values. Journal of the Royal Statistical Society, Series B (Statistical Methodology), 66(3), 497-546

22. Alonso E., Degoutte G. and H. Girard (1990). Results of seventeen years of using geomembranes in dams and basins. Proceedings of the 4th International conference on geotextiles, geomembranes and related products, Vol. 2, The Hague, The Netherlands, pp. 437-442.

23. Cazzuffi D. (1987). The use of geomembranes in Italian dams, International Water Power \& Dam Construction, Vol. 39, No. 3, pp. 17-21.

24. Carvajal C., Peyras L., Arnaud, P., Boissier D. and Royet P. (2009). Probabilistic Modeling of Floodwater Level for Dam Reservoirs, Journal of Hydrologic Engineering, 14(3), 223-232 